\title{
UPAYA MENINGKATKAN KEPUASAN TAMU MELALUI SERVICE ENCOUNTER QUALITY DI KOTA BUKIT INDAH PLAZA HOTEL PURWAKARTA
}

\author{
Yuri Puspita Pratiwi \\ Ridwan Purnama \\ Dewi Pancawati N
}

\begin{abstract}
The Hotel is one form of accommodation that supports the tourism activity. Kota Bukit Indah Plaza Hotel a four-star hotel in Purwakarta regency has a decrease at the level of customer satisfaction. To increase the customer satisfaction, Kota Bukit Indah Plaza Hotel implementation the service encounter quality is a focus of the performance of the employees by providing the best quality of service delivery currently underway, in the event of contact between employees and individual guest are referred to as the service encounters quality. The purpose of this study was to determine service encounter quality at Kota Bukit Indah Plaza Hotel, the satisfaction of guest who stayed at Kota Bukit Indah Plaza Hotel, and the effect's service encounter quality of the guest satisfaction. In this study, the independent variable $(X)$ was the service encounter quality that consisted of professionalism, civility, friendliness, and competence, and the dependent variable $(Y)$ was individual guest satisfaction. This type of research was a descriptive and verification. The systematic random sampling technique was used to distribute 100 questionnaires for the respondents. The data were analyzed by using path analysis method. The results showed that the variables of service encounter quality had a significant influence on the individual guest satisfaction.
\end{abstract}

Keywords: Service Encounter Quality, Individual Guest Satisfaction

\section{. PENDAHULUAN}

\subsection{Latar Belakang Penelitian}

Purwakarta adalah salah satu daerah di Provinsi Jawa Barat yang memiliki berbagai objek daya tarik wisata antara lain wisata alam, kuliner, seni budaya, dan perkembangan usaha akomodasi untuk menunjang kebutuhan wisatawan, salah satunya adalah hotel.

Kota Bukit Indah Plaza Hotel merupakan hotel bisnis yang berada di kawasan Industri Kabupaten Purwakarta. Hotel bintang empat ini didirikan untuk menunjang kegiatan kawasan industri yang sedang berkembang. Hotel ini merupakan hotel bisnis bernuansa resort dengan lingkungan yang hijau dan asri, jauh dari kebisingan dan keramain kota dan berada di kawasan industri sangat menunjang bagi tamu yang menginap di hotel, karena tamu yang menginap di hotel pada umumnya adalah pelaku bisnis dan para pekerja atau konsultan asing dikawasan industri Kota Bukit indah.

TABEL 1

ROOM OCCUPANCY

KOTA BUKIT INDAH PLAZA HOTEL

\begin{tabular}{|c|c|}
\hline Tahun & Occupancy Rate \\
\hline 2011 & $63,04 \%$ \\
\hline 2012 & $82,07 \%$ \\
\hline 2013 & $86,26 \%$ \\
\hline 2014 & $75,08 \%$ \\
\hline
\end{tabular}

Sumber: Front Office Kota Bukit Indah Plaza Hotel, 2014

Berdasarkan Tabel 1 dapat diketahui bahwa pada pada tahun 2011 sampai tahun 2012 mengalami peningkatan sebesar $19.03 \%$. Pada tahun 2012 sampai tahun 2013 mengalami peningkatan sebanyak $4.19 \%$. Tetapi pada tahun 2014 mengalami penurunan sebanyak $11.18 \%$. Jika hal tersebut terus dibiarkan maka akan mempengaruhi tingkat occupancy yang akan datang.

Kota Bukit Indah Plaza Hotel melakukan berbagai upaya untuk meningkatkan kepuasan tamu yang menginap agar tingkat hunian mengalami peningkatan. Berikut merupakan data kepuasaan tamu yang disajikan pada Gambar 1 di bawah ini

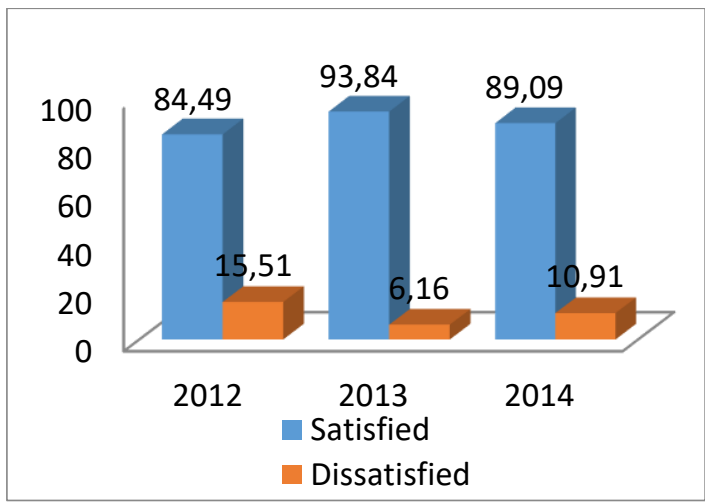

Sumber: Front Office Department Kota Bukit Indah Plaza Hotel, 2014

GAMBAR 1 OVERALL SCORE QUALITY

HOTEL OF GUEST COMMENT KOTA BUKIT INDAH PLAZA HOTEL 
Berdasarkan Gambar 1 dapat diketahui bahwa tingkat kepuasan pada tahun 2012 sampai tahun 2013 mengalami peningkatan sebesar 9,35\%. Tetapi pada tahun 2014 terjadi penurunan sebesar $4,75 \%$.

Ketidakpuasan yang dirasakan oleh tamu mengindikasikan bahwa adanya harapan dari nilai yang diiberikan oleh pihak hotel tidak sesuai dengan pengorbanan yang sudah diberikan tamu. Jika hal ini terus di biarkan akan berdampak negatif bagi hotel dan hotel akan kehilangan pelanggannya.

Meningkatkan kepuasan tamu merupakan tujuan esensial dari suatu perusahaan. Tamu yang puas akan terus menjalin relasi dengan perusahaan, sehingga kemungkinan kecil untuk melakukan switching (perpindahan merek). Kepuasan adalah hasil dari persepsi pelanggan tentang nilai yang diterima (Cronin dalam Hassan dkk, 2013:973).

Zeithaml,Bitner,Gremler

menyatakan bahwa kepuasan dipengaruhi oleh persepsi dari kualitas jasa, kualitas produk, dan harga serta faktor situasional dan faktor personal. Berdasarkan faktor pembentuk kepuasan tersebut kualitas dari sebuah jasa dapat dilihat dari persepsi tamu. Persepsi dari kualitas jasa merupakan penilaian tamu atas kualitas jasa yang diterimanya. Oleh karena itu, hotel sebagai penyedia jasa harus mengetahui setiap titik temu jasa saat tamu berinterksi dengan penyedia jasa.

Tingginya interaksi antara tamu dengan penyedia jasa dalam setiap titik temu jasa menuntut hotel untuk dapat memberikan kualitas saat pelayanan berlangsung (service encounter quality) yang sesuai dengan harapan tamu.

Berlatar belakang fenomena yang terjadi membuat penulis tertarik mengadakan penelitian dengan judul

\section{"UPAYA}

MENINGKATKAN

KEPUASAN TAMU MELALUI SERVICE ENCOUNTER QUALITY DI KOTA BUKIT INDAH PLAZA HOTEL PURWAKARTA" (Survei pada wisatawan individu yang menginap di Kota Bukit Indah Plaza Hotel Purwakarta)

\subsection{Rumusan Masalah}

Berdasarkan latar belakang di atas, maka dapat dirumuskan masalah penelitian sebagai berikut:

1. Bagaimanakah gambaran service encounter quality di Kota Bukit Indah Plaza Hotel.

2. Bagaimanakah kepuasan tamu Kota Bukit Indah Plaza Hotel.

3. Bagaimanakah pengaruh service encounter quality terhadap kepuasan tamu Kota Bukit Indah Plaza Hotel baik secara simultan maupun parsial.

\subsection{Tujuan Penelitian}

Berdasarkan rumusan masalah di atas, maka tujuan penelitian ini adalah untuk memperoleh hasil temuan mengenai:

Service encounter quality di Kota Bukit Indah Plaza Hotel.

Kepuasan tamu Kota Bukit Indah Plaza Hotel

Pengaruh service encounter quality terhadap kepuasan tamu Kota Bukit Indah Plaza Hotel baik secara simultan maupun parsial.

\subsection{Kegunaan Penelitian}

Penulisan penelitian ini diharapkan dapat memberikan manfaat kegunaan teoritis maupun praktis:

\section{Kegunaan Teoritis}

Secara teoritis, hasil penelitian ini diharapkan dapat memperluas kajian ilmu pemasaran dibidang pemasaran jasa khususnya mengenai service encounter quality yang mempengaruhi kepuasan tamu

\section{Kegunaan Praktis}

Secara praktis hasil penelitian ini diharapkan dapat memberikan masukan bagi Kota Bukit Indah Plaza Hotel dalam penentuan strategi pemasaran jasa yang berorientasi pada kepuasan pelanggan serta dapat menambah masukan bagi para pengusaha di sektor pariwisata

\section{KAJIAN PUSTAKA}

2.1 Konsep Service Encounter Quality dalam Pemasaran Jasa

Pemasaran merupakan suatu subjek produk yang sangat penting dalam pariwisata karena pemasaran merupakan serangkaian aktivitas yang dilakukan perusahaan dalam mengkomunikasikan produknya kepada konsumen yang ditujukan untuk memuaskan kebutuhan dan keinginan konsumen.

Bauran pemasaran digunakan dalam strategi pemasaran sebagai cara menarik minat konsumen agar tertarik untuk membeli barang dan jasa yang dihasilkan perusahaan. Pada bauran pemasaran tradisional dikenal dengan istilah 4 Ps yaitu product, price, place, dan promotion. Lebih jauh Lovelock (2011:44) menyebutkan bahwa perlu untuk melengkapi bauran pemasaran dengan menambah tiga Ps yang terkait dengan penyampaian jasa, yaitu process, physical environment, dan people.

Bauran pemasaran jasa dapat membuat tujuan perusahaan dicapai dengan efektif dan efisien (Fandy Tjiptono, 2011:33). Salah satunya dengan elemen people yang sangat berpengaruh terhadap persepsi jasa yang diterima konsumen. Unsur people dalam pemasaran jasa mempunyai peranan yang sangat penting, karena semua sikap dan tindakan karyawan dapat mempengaruhi persepsi konsumen terhadap sebuah jasa. Selain itu 
elemen process juga memiliki pengaruh karena saat proses penyampaian jasa, konsumen dapat mempersepsikan jasa yang diterima.

Unsur people dan process memiliki peranan penting dalam penyampaian jasa, dan jasa merupakan high contact service yaitu tingkat interaksi antara konsumen dan penyedia jasanya tinggi. Oleh karena itu penyedia jasa perlu mengetahui setiap titik temu jasa antara konsumen dan penyedia jasa yang disebut service encounter. Tingginya interaksi anatar konsumen dan penyedia jasa menuntut hotel untuk dapat memberikan kualitas saat pelayanan berlangsung (service encounter quality) Yusefyazdanpanah et al (2013:30) mengemukakan bahwa untuk mengukur keefektifan service encounter quality dapat dilihat dari empat dimensi yaitu professionalism (profesionalisme), civility (kesopanan) friendliness (keramahan), competence (kompetensi).

\subsection{Konsep Kepuasan Tamu}

Kepuasan merupakan tujuan esensial suatu perusahaan. Kata kepuasan (satisfaction) berasal dari bahasa latin "satis" artinya cukup baik (memadai) dan "facio" artinya melakukan atau membuat.

Menurut Zeithaml, Bitner, dan Gremler (2013:80) Kepuasan adalah pemenuhan respon konsumen. Hal itu merupakan penilaian mengenai fitur produk atau jasa, atau mengenai produk atau jasa itu sendiri, memberikan tingkat menyenangkan mengenai pemenuhan konsumsi terkait. Kotler \& Keller (2012:128) menyatakan Kepuasan adalah perasaan senang atau kecewa seseorang yang muncul setelah membandingkan antara persepsi atau kesannya terhadap kinerja (atau hasil) suatu produk dengan harapannya. Sedangkan Kepuasan merupakan hasil dari strategi jangka panjang yang membutuhkan dana serta sumber daya manusia. Agar tetap dapat bertahan hidup, perusahaan harus mampu menciptakan pertukaran yang berkesinambungan yang dibangun melalui perceived value $\geq$ expected value (Hasan, 2013:108).

Berdasarkan pendapat dari beberapa ahli diatas dapat disimpulkan bahwa kepuasan tamu adalah hasil dari evaluasi positif setelah membandingkan harapan dengan pengalaman konsumsi mereka atau dengan kata lain hasil dari persepsi tamu mengenai nilai yang mereka terima.

\subsection{Paradigma Penelitian}

Paradigma penelitian merupakan cara pandang peneliti dalam melihat pengaruh service encounter quality terhadap kepuasan tamu yang disajikan pada gambar 2

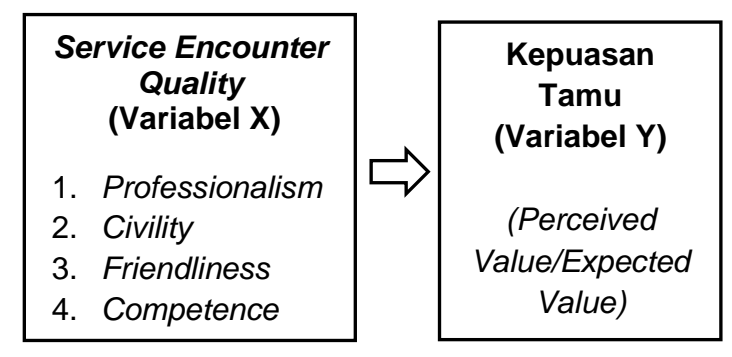

\section{GAMBAR 2 \\ PARADIGMA PENELITIAN UPAYA \\ MENINGKATKAN KEPUASAN TAMU \\ MELALUI SERVICE ENCOUNTER QUALITY \\ DI KOTA BUKIT INDAH PLAZA HOTEL}

\subsection{Hipotesis}

Berdasarkan pemaparan ini, maka peneliti mengemukakan hipotesis sebagai berikut:

"Terdapat pengaruh antara service encounter quality terhadap kepuasan tamu"

\section{METODE PENELITIAN}

\subsection{Objek Penelitian}

Penelitian ini mengenai upaya meningkatkan kepuasan tamu melalui service encounter quality di Kota Bukit Indah Plaza Hotel. Adapun yang menjadi objek penelitian sebagai variabel bebas (independent variable) adalah service encounter quality terdiri dari empat indikator yaitu profesionalism, civility, friendliness, dan competence. Sedangkan variabel terikat (dependent variable) terdiri dari dua indikator yaitu perceived value dan expected value.

\subsection{Metode Penelitian}

Berdasarkan variabel-variabel yang diteliti maka metode penelitian yang dipergunakan adalah metode penelitian deskriptif dan verifikatif.

\subsection{Metode Penarikan Sampel}

Ukuran sampel dihitung dengan menggunaan rumus Slovin (Husein Umar, 2010:131). Berdasarkan rumus tersebut, dengan derajat kesalahan sebesar 10\%, maka jumlah responden yang dijadikan ukuran sampel dalam penelitian ini ialah sebanyak 100 responden.

\subsection{Teknik Pengumpulan Data}

Teknik pengumpulan data yang digunakan oleh penulis adalah sebagai berikut:

1. Angket (Kuesioner)

2. Wawancara

3. Studi Dokumentasi

4. Studi Literatur

\subsection{Pengujian Validitas dan Reliabilitas}

Selanjutnya, sebelum didistribusikan kepada responden, instrumen penelitian yang berupa kuesioner diuji terlebih dahulu. Uji yang dilakukan 
meliputi uji validitas dan reliabilitas. Hasil menunjukan bahwa instrumen penelitian valid dan reliable

\subsection{Pengujian Hipotesis}

Proses untuk menguji hipotesis dimana metode analisis yang dilakukan dalam penelitian ini adalah metode analisis verifikatif, maka dilakukan analisis jalur (path analysis).

Adapun diagram hipotesis diterjemahkan kedalam beberapa sub-hipotesis yang menyatakan pengaruh sub-variabel independent terhadap variabel dependent, Lebih jelasnya dapat dilihat pada gambar 3 berikut:

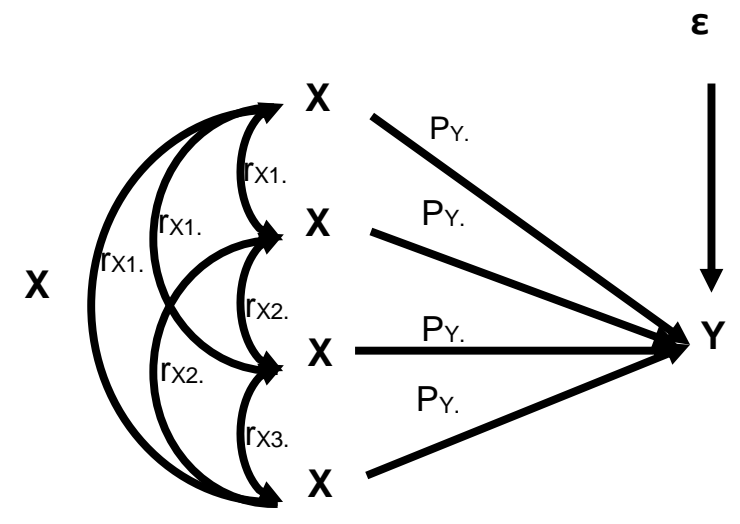

GAMBAR 3

\section{DIAGRAM STRUKTUR SUB HIPOTESIS}

Keterangan:

$\mathrm{X}_{1}=$ Professionalism

$X_{2}=$ Civility

$X_{3}=$ Friendliness

$X_{4}=$ Competence

Kriteria pengambilan keputusan hipotesis secara statistik dalam rangka pengambilan keputusan penerimaan atau penolakan hipotesis dapat ditulis sebagai berikut:

1. Hipotesis nol $\mathrm{H}_{0}: \rho=0$ maka, tidak terdapat pengaruh signifikan antara service encounter quality terhadap kepuasan tamu.

2. Hipotesis nol $\mathrm{H}_{0}: \rho \neq 0$ maka, terdapat pengaruh signifikan antara service encounter quality terhadap kepuasan tamu.

Sub hipotesis 1

$H_{0}: \rho \leq 0$, artinya tidak terdapat pengaruh yang signifikan antara professionalism terhadap kepuasan tamu

$H_{1}: \rho>0$, artinya terdapat pengaruh yang signifikan antara professionalism terhadap kepuasan tamu
Sub hipotesis 2

$H_{0}: \rho \leq 0$, artinya tidak terdapat pengaruh yang signifikan antara civility terhadap kepuasan tamu

$H_{1}: \rho>0$, artinya terdapat pengaruh yang signifikan antara civility terhadap kepuasan tamu

Sub hipotesis 3

$H_{0}: \rho \leq 0$, artinya tidak terdapat pengaruh yang signifikan antara friendliness terhadap kepuasan tamu

$H_{1}: \rho>0$, artinya terdapat pengaruh yang signifikan antara friendliness terhadap kepuasan tamu

Sub hipotesis 4

$H_{0}: \rho \leq 0$, artinya tidak terdapat pengaruh yang signifikan antara competence terhadap kepuasan tamu

$H_{1}: \rho>0$, artinya terdapat pengaruh yang signifikan antara competence terhadap kepuasan tamu

\section{HASIL PENELITIAN DAN PEMBAHASAN}

\subsection{Hasil Tanggapan Responden Terhadap Service Encounter Quality di Kota Bukit Indah Plaza Hotel}

Rekapitulasi mengenai hasil tanggapan tamu individu terhadap Service Encounter Quality di Kota Bukit Indah Plaza Hotel dapat dilihat pada Tabel 4 yang disajikan sebagai berikut 
TABEL 1

REKAPITULASI TANGGAPAN TAMU INDIVIDU ATAS SERVICE ENCOUNTER QUALITY YANG DITERIMA DI KOTA BUKIT INDAH PLAZA HOTEL

\begin{tabular}{|c|c|c|c|c|}
\hline No & Sub Variabel & $\begin{array}{c}\text { Total } \\
\text { Skor }\end{array}$ & $\begin{array}{c}\text { Rata- } \\
\text { Rata } \\
\text { Skor }\end{array}$ & $\begin{array}{c}\% \\
\text { Skor }\end{array}$ \\
\hline 1 & Professionalism & 2438 & 406,33 & 26,73 \\
\hline 2 & Civility & 2367 & 394,5 & 25,96 \\
\hline 3 & Friendliness & 4513 & 376,08 & 24,74 \\
\hline 4 & Competence & 4459 & 343 & 22,57 \\
\hline
\end{tabular}

Sumber: Hasil Pengolahan Data, 2015

Berdasarkan Tabel 1 dapat diketahui bahwa variabel yang mendapatkan skor tertinggi mengenai service encounter quality yang diterima oleh tamu individu Kota Bukit Indah Plaza Hotel adalah professionalism. Hal ini karena Kota Bukit Indah Plaza Hotel mengutamakan pelayanan yang baik yang dihasilkan dari kualitas internal yang baik, untuk menghasilkan kinerja yang maksimal dan pelayanan yang berkualitas sehingga dapat menjadi nilai tambah dalam membangun kepercayaan tamu individu.

Melihat rata-rata skor, maka disimpulkan bahwa secara keseluruhan service encounter quality di Kota Bukit Indah Plaza Hotel berada pada garis kontinum tinggi. Dengan nilai minimum yaitu 3700 dan nilai maksimum yaitu 18500 dan berada pada kategori tinggi yaitu 13700

\subsection{Hasil Tanggapan Responden Terhadap Kepuasan Tamu}

TABEL 2

\section{REKAPITULASI KEPUASAN TAMU INDIVIDU TERHADAP SERVICE ENCOUNTER QUALITY DI KOTA BUKIT INDAH PLAZA HOTEL}

\begin{tabular}{|l|l|c|l|l|}
\hline $\begin{array}{l}\text { N } \\
\text { o }\end{array}$ & Dimensi & \multicolumn{2}{|c|}{ Skor } & $\begin{array}{l}\text { Tingkat } \\
\text { Kepuasan } \\
\text { Tamu \% }\end{array}$ \\
\cline { 3 - 5 } & \multicolumn{2}{|c|}{ P } & E & \\
\hline 1 & $\begin{array}{l}\text { Professiona } \\
\text { lism }\end{array}$ & 2438 & 2674 & 91,17 \\
\hline 2 & Civility & 2367 & 2424 & 97,65 \\
\hline 3 & $\begin{array}{l}\text { Friendlines } \\
\text { s }\end{array}$ & 4513 & 5358 & 84,23 \\
\hline 4 & $\begin{array}{l}\text { Competenc } \\
e\end{array}$ & 4459 & 5546 & 80,40 \\
\hline
\end{tabular}

Sumber: Hasil Pengolahan Data, 2015
Berdasarkan Tabel 2 dapat diketahui bahwa dari empat dimensi service encounter quality terhadap kepuasan tamu individu yang menginap di Kota Bukit Indah Plaza hotel yang memiliki nilai kepuasan tertinggi terdapat pada dimensi Civility sebesar 97,65\%. Hal ini karena Kota Bukit Indah Plaza Hotel terus meningkatkan dan memberikan arahan kepada seluruh karyawan untuk memperhatikan kesopanan baik perilaku ataupun saat berkomunikasi dengan tamu individu.

Secara keseluruhan service encounter quality terhadap kepuasan tamu individu yang menginap di Kota Bukit Indah Plaza hotel memiliki nilai kepuasan sebesar 88,36\%. Termasuk kedalam kategori sangat puas dalam kriteria customer satisfaction index.

\subsection{Pengaruh Service Encounter Quality Terhadap Kepuasan Tamu di Kota Bukit Indah Plaza Hotel}

Pengujian hipotesis ini dilakukan untuk mengetahui besarnya pengaruh service encounter quality $(\mathrm{X})$ terhadap kepuasan tamu (Y). Kepuasan tamu (X) terdiri dari beberapa sub variabel yaitu professionalism $\left(\mathrm{X}_{1}\right)$, civility $\left(\mathrm{X}_{2}\right)$, friendliness $\left(\mathrm{X}_{3}\right)$, dan competence $\left(\mathrm{X}_{4}\right)$, sedangkan untuk kepuasan tamu (Y) sebagai variabel terikat memiliki indikator perceived value $\left(\mathrm{Y}_{1}\right)$, expected value $\left(\mathrm{Y}_{2}\right)$

Secara lengkap untuk mengetahui pengaruh masing-masing variabel service encounter quality terhadap kepuasan tamu disajikan pada Gambar 4 sebagai berikut:

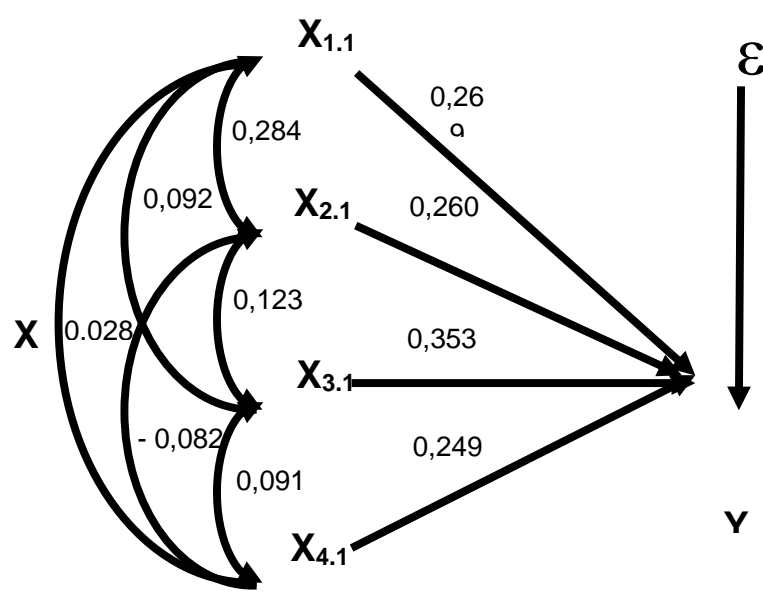

GAMBAR 4

DIAGRAM JALUR PENGUJIAN SUB HIPOTESIS 
Berdasarkan diagram jalur pengujian hipotesis pada Gambar 4, maka dilakukan perhitungan untuk mengetahui pengaruh langsung dan tidak langsung antara dimensi-dimensi sebagai berikut:

TABEL 3

HASIL PENGUJIAN KOEFISIEN JALUR PENGARUH LANGSUNG DAN TIDAK LANGSUNG SERVICE ENCOUNTER QUALITY TERHADAP KEPUASAN TAMU YANG MENGINAP

\begin{tabular}{|c|c|c|c|c|c|c|c|c|}
\hline \multirow[t]{2}{*}{$\mathbf{X}$} & \multirow{2}{*}{$\begin{array}{c}\text { Pengaruh } \\
\text { Langsung } \\
\text { Terhadap Y }\end{array}$} & \multicolumn{4}{|c|}{ Pengaruh Tidak Langsung Melalui } & \multirow{2}{*}{$\begin{array}{c}\mathbf{R}^{2} \\
\mathbf{Y} \mathbf{X}_{1}, \mathbf{X}_{2} \\
\mathbf{X}_{3}, \mathbf{X}_{4}\end{array}$} & \multirow[t]{2}{*}{ Sig } & \multirow{2}{*}{$\begin{array}{c}\text { Keputus } \\
\text { an }\end{array}$} \\
\hline & & $\mathbf{X}_{1}$ & $\mathbf{X}_{2}$ & $\mathbf{X}_{3}$ & $\mathbf{X}_{4}$ & & & \\
\hline $\mathrm{X}_{1}$ & 0,072361 & - & $\begin{array}{l}0,019862 \\
96\end{array}$ & $\begin{array}{c}0,008736 \\
04\end{array}$ & $\begin{array}{c}0,00187 \\
547\end{array}$ & $\begin{array}{l}0,102835 \\
47\end{array}$ & 0,001 & $\begin{array}{c}\text { Ho } \\
\text { ditolak }\end{array}$ \\
\hline $\mathbf{X}_{2}$ & 0,0676 & $\begin{array}{c}0,01986 \\
296\end{array}$ & - & $\begin{array}{c}0,011288 \\
94\end{array}$ & $\begin{array}{c}- \\
0,00530 \\
868\end{array}$ & $\begin{array}{l}0,093443 \\
22\end{array}$ & 0,002 & $\begin{array}{c}\text { Ho } \\
\text { ditolak }\end{array}$ \\
\hline $\mathrm{X}_{3}$ & 0,124609 & $\begin{array}{c}0,00873 \\
604\end{array}$ & $\begin{array}{c}0,011288 \\
94\end{array}$ & - & $\begin{array}{c}0,00799 \\
863 \\
\end{array}$ & $\begin{array}{c}0,152632 \\
61 \\
\end{array}$ & 0,000 & $\begin{array}{c}\text { Ho } \\
\text { ditolak }\end{array}$ \\
\hline $\mathbf{X}_{4}$ & 0,062001 & $\begin{array}{c}0,00187 \\
547\end{array}$ & $\begin{array}{c}- \\
0,005308 \\
7\end{array}$ & $\begin{array}{c}0,007998 \\
63\end{array}$ & - & $\begin{array}{c}0,066566 \\
42\end{array}$ & 0,002 & $\begin{array}{c}\text { Ho } \\
\text { ditolak }\end{array}$ \\
\hline & & & & & & & & \\
\hline
\end{tabular}

Pengujian hipotesis melalui nilai signifikansi menghasilkan penolakan terhadap Ho, karena nilai signifikansi lebih kecil dibandingkan 0,05. Hal ini berarti terdapat pengaruh yang signifikan antara service encounter quality yang terdiri dari professionalism, civility, friendliness, dan competence terhadap kepuasan tamu

Berdasarkan hasil pengujian koefisien jalur, pengaruh langsung dan tidak langsung service encounter quality terhadap kepuasan tamu, dapat diketahui bahwa professionalism (X1.1) berpengaruh langsung terhadap kepuasan tamu dengan nilai sebesar 0,072361, civility (X1.2 ) berpengaruh langsung sebesar 0,0676, friendliness (X1.3) berpengaruh langsung tertinggi sebesar 0,124609, dan competence (X1.4) berpengaruh langsung sebesar 0,062001

Pengaruh tidak langsung service encounter quality terhadap kepuasan tamu, dapat diketahui bahwa professionalism (X1.1) berpengaruh tidak langsung terhadap kepuasan tamu dengan nilai sebesar 0,10283547, civility (X1.2 ) berpengaruh tidak langsung sebesar 0,09344322, friendliness (X1.3) berpengaruh tidak langsung tertinggi sebesar 0,15263261 , dan competence (X1.4) berpengaruh tidak langsung sebesar 0,06656642

Secara keseluruhan pengaruh langsung dan tidak langsung service encounter quality terhadap kepuasan tamu sebesar $41,5 \%$ dan sisanya sebesar $(0,765)^{2}=0,585 \times 100 \%=58,5 \%$ dipengaruhi oleh faktor lain yang tidak termasuk ke dalam penelitian ini.

\subsection{Implikasi Hasil Temuan \\ 4.3.1 Temuan Penelitian Bersifat Teoritik}

Berdasarkan hasil kajian, maka dihasilkan temuantemuan teoritis sebagai berikut:

1. Berdasarkan hasil temuan penelitian, penulis memperkuat konsep service encounter quality yang dikemukakan oleh Yusefyazdanpanah et al, (2013:30) bahwa service encounter quality terdiri dari professionalism, civility, friendliness, dan competence.

2. Berdasarkan hasil temuan penelitian, penulis memperkuat konsep kepuasan yang dikemukakan oleh Hasan (2013:108) bahwa kepuasan merupakan hasil dari strategi jangka panjang yang membutuhkan dana serta sumber daya manusia. Agar tetap dapat bertahan hidup, perusahaan harus mampu menciptakan pertukaran yang berkesinambungan yang dibangun melalui perceived value $\geq$ expected value

3. Berdasarkan hasil temuan penelitian, penulis memperkuat konsep bahwa service encounter quality memiliki pengaruh yang signifikan terhadap kepuasan pelanggan. Hal ini memperkuat konsep yang dikemukakan oleh Jayawardhana (2010:338) bahwa "service encouner quality is directly related to customer satisfaction and service quality perceptions, and inderectly to perceived value and loyalty".

\subsubsection{Temuan Penelitian Bersifat Empirik}

1. Berdasarkan temuan penelitian, menunjukan bahwa service encounter quality yang dilakukan Kota Bukit Indah Plaza Hotel yang terdiri dari professionalism, civility, friendliness, dan competence berada pada garis kontinum tinggi dalam rekapitulasi keseluruhan persepsi, dimana 
dimensi professionalism memperoleh rata-rata skor tertinggi dibandingkan dengan dimensi lainnya.

2. Berdasarkan temuan penelitian, faktor pembentuk kepuasan tamu individu yang menginap di Kota Bukit Indah Plaza Hotel adalah perbandingan antara tingkatan harapan dan tingkatan kinerja dari service encounter quality yang terdiri dari professionalism, civility, friendliness, dan competence, dimana kepuasan tertinggi adalah kepuasan terhadap civility

3. Berdasarkan temuan penelitian, maka diyakini bahwa hasil penelitian ini mengukuhkan teori sebelumnya yakni service encounter quality memberikan pengaruh terhadap kepuasan tamu dan memperjelas bahwa service encounter quality efektif bagi suatu industri perhotelan yang merupakan bagian dari usaha pariwisata.

\section{KESIMPULAN DAN REKOMENDASI}

\subsection{Kesimpulan}

Berdasarkan hasil penelitian yang telah dilakukan penelitian tersebut dapat diambil kesimpulan sebagai berikut:

1. Gambaran mengenai service encounter quality yang dilaksanakan oleh Kota Bukit Indah Plaza Hotel secara keseluruhan mendapatkan penilaian cukup tinggi oleh tamu individu yang menginap di Kota Bukit Indah Plaza Hotel. Sub variabel professionalism memiliki penilaian paling tinggi oleh tamu individu. Hal ini dikarenakan karyawan selalu fokus memberikan kinerja yang maksimal dalam memberikan pelayanan terbaik pada tamu secara konsisten.

2. Kepuasan tamu individu terhadap service encounter quality di Kota Bukit Indah Plaza Hotel tergolong dalam kategori sangat tinggi. Penilaian kepuasan tertinggi terdapat pada sub variabel civility. Hal ini karena Kota Bukit Indah Plaza Hotel terus meningkatkan dan memberikan arahan kepada seluruh karyawan untuk memperhatikan kesopanan baik perilaku ataupun saat berkomunikasi dengan tamu individu.

3. Penelitian ini menunjukan bahwa service encounter quality yang terdiri dari professionalism, civility, friendiness, dan competence berpengaruh secara signifikan terhadap kepuasan tamu individu yang menginap di Kota Bukit Indah Plaza Hotel sebesar $41,5 \%$, hal ini menunjukan bahwa terdapat pengaruh yang cukup kuat antara service encounter quality terhadap kepuasan tamu individu yang menginap di Kota Bukit Indah Plaza Hotel, dan sisanya 58,5\% dipengaruhi oleh faktor lain yang tidak termasuk kedalam penelitian penulis. Pengaruh tertinggi yaitu terdapat pada sub variabel friendliness, hal ini karena Kota Bukit Indah Plaza Hotel telah menerapkan standar pelayanan kepada semua karyawan mengenai cara berperilaku dan berkomunikasi dengan tamu dengan baik sehingga tercipta kehangatan dan keakraban yang terjalin antara tamu individu dengan karyawan yang dapat membuat tamu merasa nyaman telah menggunakan produk di Kota Bukit Indah Plaza Hotel.

\subsection{Rekomendasi}

Berdasarkan hasil penelitian yang diperoleh, maka penulis menyarankan hal-hal sebagai berikut:

1. Berdasarkan hasil penelitian dapat diketahui bahwa tingkat kepuasan tamu yang memiliki penilaian terendah yaitu sub variabel competence. Penulis menyarankan agar perusahaan mengadakan pelatihan-pelatihan kepada karyawan untuk menambah wawasan dan meningkatkan skill karyawan.

2. Dalam mengimplementasikan service encounter quality di Kota Bukit Indah Plaza Hotel melibatkan beberapa department, diantaranya security department, front office depatment, food and beverage departemnt dan housekeeping department. Penulis menyarankan agar perusahaan tidak hanya mengadakan training product knowledege tetapi juga melakukan training berupa pembekalan physcology of service sehingga karyawan lebih dapat memahami kebutuhan tamu individu dan perlu diadakan cross training untuk masing-masing department, sehingga kualitas kinerja yang diharapkan dapat maksimal, dan akan berdampak terhadap pelayanan yang akan diberikan kepada tamu.

3. Penelitian ini masih terdapat banyak kekurangan, salah satunya yaitu pada teori-teori pendukung yang digunakan masih kurang lengkap dan penelitian ini dilakukan hanya dalam satu hotel, penulis merekomendasikan penelitian selanjutnya dapat membandingkan antara satu hotel dengan hotel lainnya dengan menambah teori-teori baru yang mendukung sehingga lebih memperkuat sebuah penelitian.

\section{DAFTAR PUSTAKA}

Ali Hasan. 2013. Marketing dan Kasus - kasus pilihan. Jakarta: Center Academi Publishing Service

Kota Bukit Indah Plaza Hotel Issued Report

Lovelock, Chirstoper \& Jochen Writz. 2011. Service Marketing, People, Technology, Strategy $7^{\text {th }}$ Edition.New Jersey USA: Pearson.

Tjiptono, Fandy. 2011. Pemasaran Jasa. Jawa Timur: Bayumedia Publishing

Umar, Husein. 2010. Metode Penelitian Untuk Skripsi dan Tesis Bisnis. Jakarta: Rajagrafindo Persad

Yusefyazdanpanah, Feizi Mohammad, 
HasanzadehMahmoud Abad Mohammad. 2013. Relative importance of service encounter quality dimensions and customer satisfactionin Meshkin City's MellatBank. Vol.1

Zeithaml, Valarie A, Mary Jo Bitner,

Gremler Dwaine D. 2013. Services Marketing "Integrating Customer Focus Across The Firm". International Edition. McGraw Hill. 